\title{
Impact on operation of the Middle Route Project of South-to-North Water Diversion
}

\author{
Hui Wan ${ }^{\text {a }}$ Huiyong Huang, Sidong Zeng, Yibo Yan, Yongyan Wu, Shaohua Liu, Kai Wei \\ Changjiang Survey, Planning, Design and Research Co. , Ltd. , Wuhan 430010, China
}

\begin{abstract}
The inter-basin water transfer project is one of the most important means to solve the uneven distribution of water resources in time and space, rationally allocate water resources, and promote the construction of water ecological civilization. Research on the operation impact and channel hydraulic response is meaning for the safe operation of long-distance water conveyance canals. Taking the Middle Route Project (MRP) of South-to-North Water Diversion (SNWD) as example, this paper built the onedimensional steady and unsteady flow model and investigated the impact of roughness change, emergency rescue technology and equipment, and sluice control failure. Results showed that increased roughness decreased the water diversion efficiency of MRP to some degree. The emergency rescue technology and equipment occupied the channel section and declined flow capacity. The occurrence of sluice control failure relatively played an increasing impact on upstream water level and a decreasing impact downstream water level and flow discharge. The impact of the above scenarios on the scheduling operation can be reduced to a certain extent by regular cleaning and maintenance, development of rational water emergency rescue project, development of staff skill, etc. This research can provide support for safe operation and regulation of the MRP of SNWD.
\end{abstract}

\section{Introduction}

The Middle Route Project (MRP) of the South-to-North Water Transfer Project (SNWD) diverts water from the Danjiangkou Reservoir, and supplies water to Henan, Hebei, Beijing and Tianjin all the way to the north, with a total length of $1432 \mathrm{~km}$. It is one of the most effective means to alleviate the uneven distribution of water resources in Beijing, Tianjin and North China, rationally allocate water resources and promote the construction of water ecological civilization. The design flow and extra flow of the head works are respectively $350 \mathrm{~m}^{3} / \mathrm{s}$ and $420 \mathrm{~m}^{3} / \mathrm{s}$, and the average annual water transfer volume is 9.5 billion $\mathrm{m}^{3}$. As of September 2018, MRP has been continuously supplied with water safely for more than 1,370 days, with a total water transfer volume of 16.929 billion $\mathrm{m}^{3}$, which has ensured the safety of water diversion in the water receiving area, improved the water supply guarantee rate, and increased the total happiness of the people. However, MRP is a long water delivery line with mixed types of control buildings, large quantities, and strict water supply requirements, resulting in huge difficulty in long-distance water supply channel operation control and serious threat to safe operation. Therefore, it is of great significance to study the factors affecting the normal operation and the countermeasures of MRP to ensure the safe water supply of the water transfer project, the ecological and environmental, social and economic benefits.
Some scholars have achieved a series of achievements and progresses on the impact of the operation control of MRP. Huang[1] summarized four kinds of flow volume changes, and obtained the initial control strategy of MRP water control scheduling. Zhou[2] proposed the operation control mode and management measures for MRP. Lian[3] studied the emergency shutdown time to control the diffusion range of pollution clouds with $\mathrm{Hec}$ ras. According to the QUAL-II water quality model, Chen[4] constructed a one-dimensional water quality numerical simulation model considering the mutual conversion reaction between nine water quality variables and investigated the emergency control strategies for the pollution channel pool, upper and lower section gates. Fang[5] compared and analysed the stability time, water withdrawal volume, water level variation and pollutant concentration of the emergency control strategy when the backwater gate is activated and not activated in MRP. Nie[6] proposed that the target water level before the gate of MRP during emergency operation should be closer to the increased water level from the perspective of comprehensive consideration of safety and economy. As to the Tianjin canal, Fang[7] simulated the influence of different control modes on the main canal flow during the change of the water distribution flow in Tianjin. Zeng[8] researched the response process of the hydraulic transition of Tianjin canal under different water flow rates to the pumping and replenishment of the Wangqingtuo Reservoir from the Tianjin canal.

\footnotetext{
a Corresponding author: wanhui@cjwsjy.com.cn
} 
These studies focused on the scheduling operation control strategies such as design stage and unconventional working conditions. According to the actual operation of MRP in the past 4 years, the change of the channel roughness, the occupation flow section of emergency rescue equipment, and the failure of the gate control operation, have become ones of the main threats to the normal dispatching operation of MRP. This study selected the MRP of SNWD as the research object, investigated the impacts of change of the channel roughness, the occupation flow section of emergency rescue equipment, and the failure of the gate control on Hydraulic characteristics such as channel water level and flow discharge via one-dimensional steady and unsteady flow model, and discussed on response measures combining existing operational management experience.

\section{Methodology}

\subsection{Mathematical model}

\subsubsection{Steady flow}

The basic equation for steady flow calculation in MRP is the energy equation, which is suitable for open channels, aqueducts, inverted siphons. The equation is as follows,

$$
Z_{1}+\frac{p_{1}}{\gamma}+\frac{\alpha_{1} u_{1}^{2}}{2 g}=Z_{2}+\frac{p_{2}}{\gamma}+\frac{\alpha_{2} u_{2}^{2}}{2 g}+h_{w}(1)
$$

where $z$ is water level; $p$ is pressure; $u$ is velocity; $a$ is kinetic energy correction factor with normal value set as $1 ; h_{w}$ is head loss including frictional head loss and local head loss. The subscript 1 and 2 represent upstream and downstream section relatively.

\subsubsection{Unsteady flow}

The MRP has a long water delivery channel with a low slope and a smooth water flow. The Saint-Venant equations can be used to describe the basic equations of one-dimensional unsteady flow. The continuous equation and the momentum equation are expressed as follows.

$$
\begin{gathered}
\frac{\partial Q}{\partial x}+\frac{\partial F}{\partial t}+q=0(2) \\
\frac{\partial Z}{\partial x}+\frac{u}{g} \frac{\partial u}{\partial x}+\frac{\partial u}{g \partial t}+\frac{u^{2}}{c^{2} R}-\frac{2 u q}{g F}=0(3)
\end{gathered}
$$

where $Q$ is flow discharge; $F$ is section area; $c$ is Chezy coefficient; q is outflow from the unit channel length. For low-pressure buildings such as inverted siphon, it is assumed that the water flow density $\rho$, bulk density $\gamma$ are constant. formula (2) is also suitable to inverted siphon via changing the water level $z$ into the piezometric head $H=z+p / \gamma$.

\subsubsection{Sluice discharge flow}

The Henrry formula is adopted to the sluice discharge flow of MRP. This formula can basically guarantee the continuity of flow under various opening degrees. The expression is as follows,

$$
Q=C_{d} e b \sqrt{2 g h_{0}}(4)
$$

where $e$ is the gate opening; $b$ is the gate net width; $h_{0}$ is the upstream water level; $C_{d}$ is the discharge coefficient, which is the application difficulty of the Henrry formula, and the relevant value is listed in the literature[6].

\subsection{Solution of Equation}

The steady flow model calculation starts from the end control gate and proceeds from the downstream to the upstream until the head sluice. Due to the nonlinearity of the steady flow model, the iterative method is used to calculate the water level and flow discharge between sluices until the error does not exceed the allowable value.

The Preissmann implicit difference method with good stability, fast convergence and high precision is adopted to the unsteady flow model calculation to solve the SaintVenant equations discretely. Related expressions are referred to the literature[6].

\section{Research scenarios}

\subsection{Roughness increasement}

The whole open channel was selected to investigate influence of roughness change on normal operation. The total length of the open channel of MRP is $1197.7 \mathrm{~km}$, involving 61 gates. The water level gap between the first and the last gate is $88.38 \mathrm{~m}$. The cover of MRP is Smooth concrete, the integrate roughness of which is 0.015 according to [9]. As the operation time prolongs, various algae and silt accumulate, resulting in an increasingly rough cross section of the canal and increased roughness. This study compared the effect of the roughness which increased to 0.016 on the overcurrent capacity of the channel.

\subsection{Emergency rescue technology and equipment}

The MRP has become an important water source of along the route, and even the only water source for some areas. Although the MRP has operated with highly security and stability for a long time and major emergency that poses a serious threat to the project never occurred, several channel slopes were damaged slightly. In order to avoid water leakage, these damaged slopes need to be repaired with uninterrupted water supply. In this study, a channel about $90 \mathrm{~m}$ long in Henan Province was taken as an example to analyze the impact of emergency rescue technology and equipment overburden cross section on the flow capacity in the design conditions. The design flow and the extra flow rate of the channel are $295 \mathrm{~m}^{3} / \mathrm{s}$ and $355 \mathrm{~m}^{3} / \mathrm{s}$ respectively. Both the upstream and downstream sluice gate are 4 holes, and the control building types a of sluice control failure re inverted siphons. 


\subsection{Sluice control failure}

The water diversion status of MRP is from the initial low water level and small flow discharge to high water level and small flow discharge, and is gradually approaching the design state. The different flow of the sluice gate corresponds to different gate openings. Under different gate flow discharge, the hydraulic response of the total channel to the failure gate opening is different. In this study, $75 \%$ of the design flow was selected as the calculation scenario, taking the normal steady water level and flow before the gate failure as the initial condition. Correspondingly, the one-dimensional steady flow mathematical model was adopted to calculate the initial water surface. When the gate control failure occurs, the original boundary conditions are kept unchanged, and the water diversion flows of each turn-out gate are unchanged as well. The return gates are closed, and the normal gates maintain the original openings. Respectively, the onedimensional unsteady flow mathematical model was chose to simulate the channel hydraulic response, which was contrasted to the initial condition to study the influence of gate control failure on channel operation. The Diaohe sluice is located in the front of MRP and the control building type is aqueducts which consist of two holes with the biggest design flow discharge of $175 \mathrm{~m}^{3} / \mathrm{s}$ for each. Therefore, the Diaohe sluice is suitable and typical for the of sluice control failure research.

\section{Results}

\subsection{Impacts of roughness increasement}

When the whole channel roughness increased to 0.016 , the head loss increases as well. In order to guarantee the design overcurrent capability, some of the sluice gates need to exit the operation and do not participate in the hydraulic control. It was calculated that the 19 sluice gates will be out of control operation between the Taocha sluice and the Beijuma sluice. The upstream water level variation of sluices compared to the design water level was shown in Figure 1. Those upstream water level kept unchanged were not listed. As can be seen from the Figure 1 , when the roughness increased to 0.016 , upstream water levels of sluices that exited operation rose at most $0.11 \mathrm{~m}$ higher than the original design ones. $31.1 \%$ sluices which were out of operation meant reduced and more difficult control.

From the perspective of flow discharge, when the whole channel roughness increased to 0.016 , the flow capacity of the channel was required to be reduced in order to ensure the design water level. It was analysed that the maximum overcurrent capacity of the Taocha sluice was $330.7 \mathrm{~m}^{3} / \mathrm{s}$, which was $5.5 \%$ lower than the original design flow. Similarly, the maximum overflow capacity of the Chuanhuang sluice was $245.7 \mathrm{~m}^{3} / \mathrm{s}$, which was $7.3 \%$ lower than the original design flow.

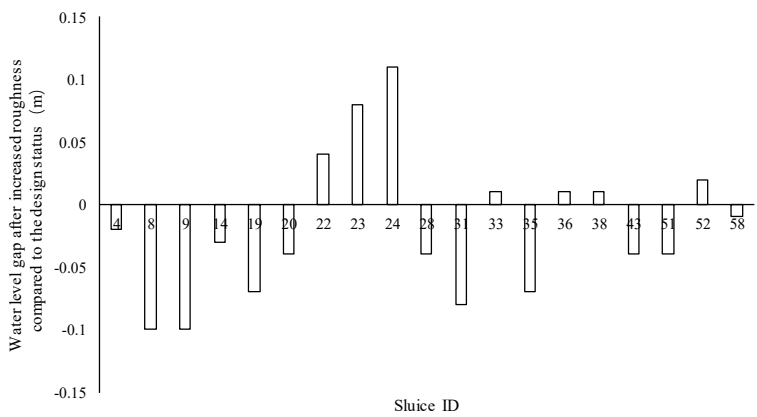

Figure 1. Influences of the roughness of the whole channel increased to 0.016 on the water level of the sluices

\subsection{Impacts of emergency rescue technology and equipment}

Table 1 showed the impacts on the hydraulic characteristics of a certain section in Henan Province due to emergency rescue technology and equipment occupying flow section. And the water level variations of the relevant section were displayed in Figure 2. It can be seen from Table 1 that the upstream water level was backed up under the uncontrolled velocity rescue condition. Due to the proximity of the upstream sluice gate, the sluice downstream water level approached to the design water level, which caused the upstream sluice gate should be out of control to ensure the original flow overcurrent. Through iterative calculation, it was found that only when the overcurrent flow was reduced from $295 \mathrm{~m}^{3} / \mathrm{s}$ to $274.4 \mathrm{~m}^{3} / \mathrm{s}$, can all sluice gates be guaranteed to participate in the operation control according to the design conditions. In this case, the water level in the downstream of the rescue section decreased, and correspondingly the hydraulic gradient and gate opening increased. The flow velocity of the rescue section also increased from $1.09 \mathrm{~m} / \mathrm{s}$ to $1.33 \mathrm{~m} / \mathrm{s}$, with an increase rate at $22 \%$. Therefore, the channel overcurrent capacity was reduced by $7.0 \%$, which was lower than the reduced rate of section area.

Under the condition of velocity control rescue to maintain the original flow velocity, the upstream and downstream water level was reduced by $0.24 \mathrm{~m}$ and $0.18 \mathrm{~m}$ respectively. The section area was greatly reduced as well, resulting in a reduction in overcurrent flow to $191.3 \mathrm{~m}^{3} / \mathrm{s}$, which was of $35.2 \%$ lower than the design flow. It could be seen that the velocity control rescue condition imposed strong constraints and restrictions on the water supply capacity of the relevant channel. The 60-day rescue program would reduce 537 million $\mathrm{m}^{3}$ water volume, which greatly affected the water supply efficiency of MRP

\subsection{Impacts of sluice control failure}

In order to ensure the safety of MRP, the maximum backed up upstream water level is determined to the extra water level plus $0.1 \mathrm{~m}$, and the maximum daily water level decrease rate is $0.3 \mathrm{~m} / \mathrm{d}$. Those constraints are also applicable to the analyse of impacts of sluice control failure. Figure 3 showed the Diaohe sluice upstream and 
downstream water level and flow discharge compared to normal condition when one of the sluices was totally shut down. It was observed that the sluice upstream level increased and did not exceed the limit. However, the sluice downstream level decreased and the rate exceeded the allowable limit, which might threat to channel safety. The variation of water level increased with the extension of the failure time.

The flow discharge was reduced and the decrement decreased with the extension of the failure time. This change in the flow discharge was closely related to the fluctuation of the water level and affected each other. According to formula (4), although the effective opening was reduced, the upstream water level increased, and the downstream water level decreased. The discharge coefficient $C_{d}$ was changed consequently, which exhibited the nonlinearity of the sluice discharge flow formula. The complex relationship between water level and flow discharge explained the variation of water level in Figure 3. The upstream and downstream water levels maintained a certain stability during some periods, instead of a sustained climbing or falling.

Table 1. Influences of emergency rescue technology and equipment on the hydraulic characteristics

\begin{tabular}{|l|l|l|l|}
\hline & $\begin{array}{l}\text { original } \\
\text { design } \\
\text { condition }\end{array}$ & $\begin{array}{l}\text { uncontrolled } \\
\text { velocity } \\
\text { rescue } \\
\text { condition }\end{array}$ & $\begin{array}{l}\text { controlled } \\
\text { velocity } \\
\text { rescue } \\
\text { condition }\end{array}$ \\
\hline $\begin{array}{l}\text { Section } \\
\left.\text { area(km }{ }^{2}\right)\end{array}$ & 270.6 & 206.2 & 175.2 \\
\hline $\begin{array}{l}\text { Section } \\
\text { velocity(m/s) }\end{array}$ & 1.09 & 1.33 & 1.09 \\
\hline $\begin{array}{l}\text { velocity } \\
\text { variation rate(\%) }\end{array}$ & - & 22 & - \\
\hline $\begin{array}{l}\text { Flow } \\
\left.\text { discharge(m } \mathrm{m}^{3} / \mathrm{s}\right)\end{array}$ & 295 & 274.4 & 191.3 \\
\hline $\begin{array}{l}\text { discharge } \\
\text { variation rate(\%) }\end{array}$ & - & -7 & 35.2 \\
\hline $\begin{array}{l}\text { upstream water } \\
\text { level gap(m) }\end{array}$ & - & 0.02 & -0.24 \\
\hline $\begin{array}{l}\text { downstream } \\
\text { water } \\
\text { gap(m) }\end{array}$ & - & -0.02 & -0.18 \\
\hline $\begin{array}{l}\text { Upstream sluice } \\
\text { gate opening(m) }\end{array}$ & 4.43 & 4.52 & 3.32 \\
\hline $\begin{array}{l}\text { Influence } \\
\text { scope(km) }\end{array}$ & - & 11.439 & 11.439 \\
\hline
\end{tabular}

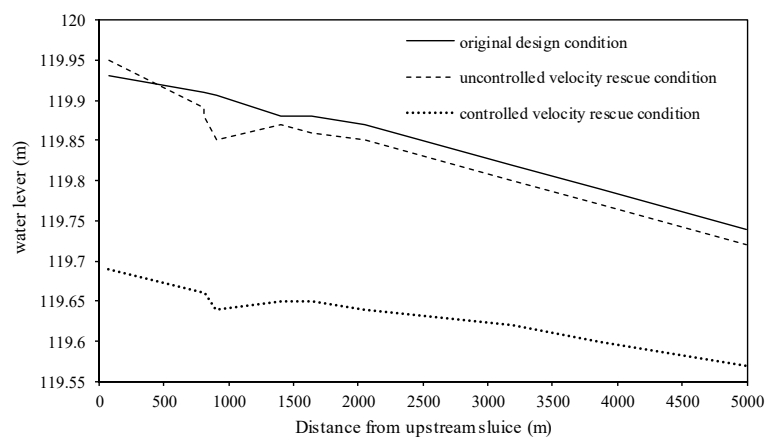

Figure 2. Influences of emergency rescue technology and equipment on the water level of the relevant canal

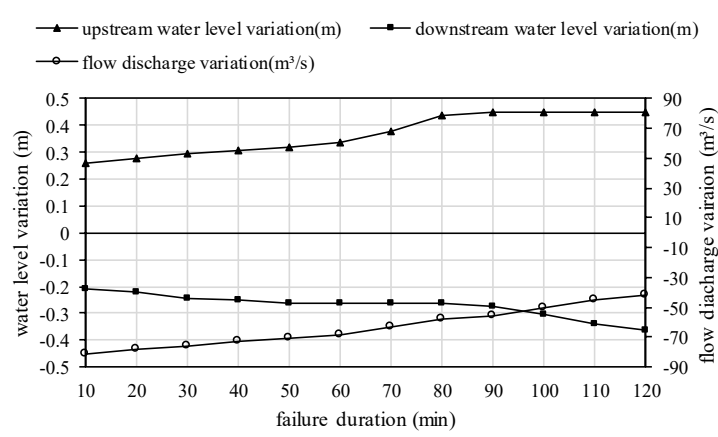

Figure 3. Influences of the Diaohe sluice control failure on water levels and flow discharges

\subsection{Response measures researches}

The increase in roughness will reduce the efficiency of water supply of MRP to a certain extent. With the extension of time, the roughness change along the channel is unavoidable. Fortunately, the change is very slow instead of sudden. Therefore, the impact on operations can be reduced by regular cleaning and maintenance.

Emergency rescue technology and equipment occupy the channel section, which also reduce the water supply capacity of MRP to a certain degree. It can be seen in the case of uncontrolled velocity rescue that increased the hydraulic gradient can increase the flow velocity, which can improve the overcurrent capacity and reduce the impact of emergency rescue technology and equipment on rescue channel. Through trial and error analysis, it was found that when the upstream water level was increased by $0.2 \mathrm{~m}$ from the design water level, the flow velocity could be increased to $1.58 \mathrm{~m} / \mathrm{s}$ and the original design flow capacity could be ensured as well. In this case, other sluices operations were not affected and the influence scope could be reduced from $11.44 \mathrm{~km}$ (Table 1) to $1.64 \mathrm{~km}$. Attention should be paid to the reality that the permitted flow velocity of the rescue section is determined by the anti-sliding stability of the rescue technology and equipment. Increasement of slip stability means increasement in weight and cost. Therefore, in the rescue technology and equipment development, the balance between investment, practicality and influence on hydraulics should be highly valued.

According to the previous results of water level fluctuation analysis, this study analysed the effect of emergency operation measure at the 30th and 60th minutes by regaining the gate opening. The durations were both $30 \mathrm{~min}$. Results were illustrated in Figure 4 and 5 respectively. It could be seen from Figure 4 and 5 that both measures could reduce backed up upstream water level and enhance the downstream water level. The flow discharge increased first and then steadily approached the design flow. Comparing the two emergency operation measures, it could be observed that the earlier the emergency operation started, the shorter the time was needed to return to the normal status, and the better to reduce of the gate failure impact. It was worth noting that the premise of the emergency operation measures for adjusting the failure gate opening was that the gate can still be adjusted, and the staff needed to improve the 
efficiency and technical level. If the gate was stuck and cannot be operated, it can be adjusted by other gates or adjacent sluices, turn-out gates, and return gates to maintain normal water supply and safe operation.

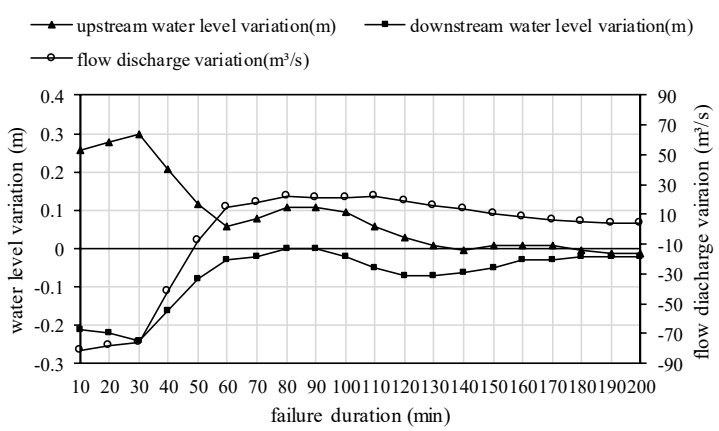

Figure 4. Effects of emergency operation measure of fault gate opening of Diaohe Sluice at the $30^{\text {th }} \mathrm{min}$

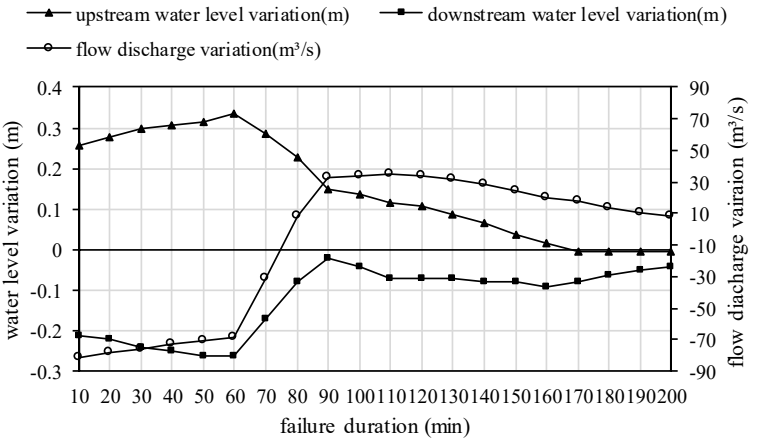

Figure 5. Effects of emergency operation measure of fault gate opening of Diaohe Sluice at the $60^{\text {th }} \mathrm{min}$

\section{Conclusions}

Based on the one-dimensional steady and unsteady flow mathematical model, this study took the MRP of SNWD as research object to investigate the possible conditions that may impact normal operation. Hydraulic response mechanism of long-distance water diversion project to roughness change, emergency rescue technology and equipment, and gate control operation failure were explored and reasonable and feasible countermeasures were investigated. Results showed that increased roughness decreased the water diversion efficiency of MRP to some degree. The emergency rescue technology and equipment occupied the channel section and declined flow capacity. The occurrence of sluice control failure relatively played an increasing impact on upstream water level and a decreasing impact downstream water level and flow discharge. The impact of the above scenarios on the scheduling operation can be reduced to a certain extent by regular cleaning and maintenance, development of rational water emergency rescue project, development of staff skill, etc. This research can provide support for safe operation and regulation of the MRP of SNWD.

\section{Acknowledgements}

This paper was supported by the National Key Research and Development Program of China (No. 2017YFC0405006 and No.2016YFC0401810), the
National Natural Science Foundation of China (No. 51809008), Independent research project of C.I.S.P.D.R. (CX2017Z03)

\section{References}

1. H.Y. Huang, Z.H. Liu, J. Fan, W.Y Mao, Z.Y. Wu. Yangtze River. 43(5), 13-18(2012).

2. M. Zhou, J.J. Lian, X. Cheng, X. Zhao. Yangtze River, 47(21), 106-109(2016)

3. J.J. Lian, X. Wang, C.Y. Liu, C. Ma. J. Tianjin Uni. (Science and Technology), 46(1), 44-50(2013)

4. X. Chen. (Doctoral dissertation, IWHR (2015)

5. Y.M. Fang, D.W. Zhang, X.H. Lei, H.M. Wu, G.Q. Sang. SNWT. Wa. Sci, Te., (2), 133-136(2014)

6. Y.H. Nie, G.B. Huang, X. Cui. Yangtze River, (4), 6769 (2015)

7. S.G. Fang, B.S. Wu, \& X.D. Fu. J. Hrdro. Eng., 27(5), 93-97(2008).

8. S.D. Zeng, H.Y. Huang, \& Y.B. Yi. SNWT. Wa. Sci, Te.(a02), 134-137(2016)

9. X. Zhao, X.Y. Zhang, M.D. Zhao, H.Y. Tong. Hydraulics(China Electric Power Press, 2009) 